\title{
Synthesis, chemical speciation and SOD mimic assays of tricarballylic acid-copper(II) and imidazole-tricarballylic acid-copper(II) complexes
}

\author{
Luciana Naso $^{\mathrm{a}}$, Ana C. González Baró ${ }^{\mathrm{a}}$, Luis Lezama ${ }^{\mathrm{b}}$, Teófilo Rojo ${ }^{\mathrm{b}}$, Patricia A.M. Williams ${ }^{\mathrm{a}}$, \\ Evelina G. Ferrer ${ }^{\mathrm{a}, *}$ \\ ${ }^{a}$ CEQUINOR (Centro de Química Inorgánica), Facultad de Ciencias Exactas, Universidad Nacional de La Plata, 47 y 115 (1900) La Plata, Argentina \\ ${ }^{\mathrm{b}}$ Departamento de Química Inorgánica, Facultad de Ciencia y Tecnología, Universidad del País Vasco, Apdo 644, 48080 Bilbao, Spain
}

\section{A R T I C L E I N F O}

\section{Article history:}

Received 3 June 2008

Received in revised form 8 October 2008

Accepted 8 October 2008

Available online 17 October 2008

\section{Keywords:}

Tricarballylic acid

EPR

$\mathrm{Cu}(\mathrm{II})$ complexes

Speciation

SOD activity

\begin{abstract}
A B S T R A C T
The coordination behavior of copper(II) with tricarballylic acid $\left(\mathrm{H}_{3} \mathrm{TCA}\right)$ and imidazole (Imz) is described. Speciation in aqueous solution has been determined at $25^{\circ} \mathrm{C}$ and $0.15 \mathrm{M} \mathrm{NaCl}$ ionic strength by potentiometric measurements and EPR characterization of the species. Two new compounds $\mathrm{CuTCAH} \cdot 3 \mathrm{H}_{2} \mathrm{O}$ and CuTCAHImz $\cdot 2 \mathrm{H}_{2} \mathrm{O}$ were obtained and characterized by elemental analysis diffuse reflectance, FTIR (Fourier transform infrared spectroscopy), EPR and thermal behavior. Their in vitro superoxide dismutase-mimetic activities have been tested.
\end{abstract}

(c) 2008 Elsevier Inc. All rights reserved.

\section{Introduction}

One of the most studied topics in bioinorganic chemistry is the biologically interesting interaction of biometals, biomolecules and bioligands [1-3]. The role of metal ions in the biological activity of metalloproteins, nucleic acids and peptide hormones is fundamental in understanding the principles that govern selectivity and specificity of macromolecules [3]. In this context, the study of the interaction between copper(II) and tricarballylic acid (1,2,3propanetricarboxylic acid, $\left.\mathrm{H}_{3} \mathrm{TCA}\right)$, has been performed.

The polycarboxylic acid $\mathrm{H}_{3}$ TCA is a small biomimetic ligand. It is present in several natural products as Fumonisin B1, B2, AAL Toxin TA and it is a fragment of the inhibitor of farnesyl-protein transferase (FPTase) [4,5]. In the living organisms, $\mathrm{H}_{3}$ TCA is related to malfunctions [6] and due to its participation in the zinc excretion through the interaction and chelation with this metal ion [7] it is suggested that it is partly responsible for the deficiency of $\mathrm{Zn}$. On the other hand, in recent years, polycarboxylic acids (bi and tricarboxylic) have attracted the attention of many researchers because of their participation as building blocks in metal-organic frameworks $[8,9]$. There are few reports about the study of metal complexes with $\mathrm{H}_{3}$ TCA and related polycarboxylic acids [10-13].

It is well known that trace amounts of copper are essential for life and that an excess of this element has toxic effects (Wilson

\footnotetext{
* Corresponding author. Tel./fax: +54 02214259485.

E-mail address: evelina@quimica.unlp.edu.ar (E.G. Ferrer).
}

disease). Therefore it is necessary to know which are the specific mechanisms for copper to be available in order to prevent its accumulation or deficiency. In living organisms, copper forms complex compounds, involving either small molecules or proteins, which behave as carrier-transporter molecules. The studies of the binding properties and the nature of the binding site have become an area of research interest $[1,14]$.

In addition, some copper(II) complexes containing similar ligands where found to have a variety of pharmacological and biological activities which encompass antiarthritis and antimicrobial, among others [15-18]. This activity is usually associated with a particular coordination environment of the metal in the active site. In the case of copper, several metalloproteins are known: ascorbate oxidase, ceruloplasmin, azurin $\mathrm{Cu}, \mathrm{Zn}$ superoxide dismutase [19].

On the other hand, low molecular weight complexes of transition metals, especially those of copper, were prepared and studied as interesting models of biological systems and biomaterials. Indeed, several $\mathrm{Cu}$ (II) compounds of $\mathrm{N}$-containing small bioligands have a striking interest because they mimic superoxide dismutase (SOD) activity [20,21].

Taking into account that several biomolecules interact with biometals through their nitrogen atoms when $\mathrm{N}$-ligands are present in the coordination sphere of SOD mimetic complexes, an improvement of their activity has been detected. Therefore the study of the interaction of copper with $\mathrm{H}_{3}$ TCA and imidazole is included herein.

In general, the chemical speciation profile of an element, either essential or toxic, allows the knowledge of its biodisponibility, 
transport and absorption properties in biofluids or tissues as well as their environmental impact [22,23]. In order to perform a complete equilibrium study of the $\mathrm{Cu} / \mathrm{TCA} / \mathrm{Imz} / \mathrm{H}^{+}$system in solution, the $\mathrm{Cu} / \mathrm{TCA} / \mathrm{H}^{+}$system has been reinvestigated in the present conditions.

Besides, the in vitro SOD like activity of the compounds has also been evaluated.

\section{Experimental part}

\subsection{Reagents and instrumentation}

All chemicals were of analytical grade. Copper(II) chloride dihydrate (Merck), tricarballylic acid (Sigma), and imidazole (Riedel de Haën) were used as purchased. Nitroblue tetrazolium (NBT), xanthine and xanthine oxidase, phenazine methosulfate (PMS), NADH and all the other chemicals used were of analytical grade (Sigma).

IR spectra of powdered samples were measured with a Bruker IFS 66 FTIR-spectrophotometer from 4000 to $400 \mathrm{~cm}^{-1}$ in the form of pressed $\mathrm{KBr}$ pellets. Electronic absorption spectra were recorded on a Hewlett-Packard 8453 diode-array spectrophotometer, using $1 \mathrm{~cm}$ quartz cells. Diffuse reflectance spectra were registered with a Shimadzu UV-300 instrument, using $\mathrm{MgO}$ as an internal standard. Elemental analyses for carbon, hydrogen and nitrogen were performed using a Carlo Erba EA 1108 analyzer. Thermogravimetric (TG) and differential thermal analysis (DTA) were performed on a Shimadzu system (models TG-50 and DTA-50, respectively), working in an oxygen flow $(60 \mathrm{~mL} / \mathrm{min})$ at a heating rate of $10^{\circ} \mathrm{C} / \mathrm{min}$. Sample quantities ranged between 10 and $20 \mathrm{mg}$. $\mathrm{Al}_{2} \mathrm{O}_{3}$ was used as a DTA standard. A Bruker ESP300 spectrometer operating at $\mathrm{X}$ and $\mathrm{Q}$-bands and equipped with standard Oxford low temperature devices was used to record the EPR spectra of the compounds at different temperatures. The magnetic field was measured with a Bruker BNM 200 gaussmeter, and the frequency inside the cavity was determined by using a Hewlett-Packard 5352B microwave frequency counter. Anisotropic X-band EPR spectra of frozen solutions were recorded at $140 \mathrm{~K}$, after addition of $10 \%$ ethylene glycol to ensure good glass formation. A computer simulation of the EPR spectra was performed using the programs SimFonia [24]. All spectroscopic measurements were carried under high-purity nitrogen atmosphere and the concentrations ratios were the same as used in the potentiometric titrations. The potentiometric measurements were performed with a Schott Gerate TS165 pH meter using a Schott Titronic 96 automatic burette for titrant addition.

\subsection{Preparative}

\subsection{1. $\mathrm{CUTCAH} \cdot 3 \mathrm{H}_{2} \mathrm{O}$}

The complex was prepared by mixing aqueous solutions of $\mathrm{CuCl}_{2} \cdot 2 \mathrm{H}_{2} \mathrm{O}(1 \mathrm{mmol}, 0.170 \mathrm{~g}$, dissolved in $10 \mathrm{~mL})$ with $\mathrm{H}_{3} \mathrm{TCA}$ $(1 \mathrm{mmol}, 0.176 \mathrm{~g}$ in $10 \mathrm{~mL})$ under continuously stirring. Afterwards, the $\mathrm{pH}$ of the solution was adjusted at 4 by adding small aliquots of $1 \mathrm{M} \mathrm{NaOH}$ solution. The resulting mixture was stirred for $20 \mathrm{~min}$ and a blue solid product was filtered off and discarded because it contained more than one species as it has been detected by EPR spectroscopy. From the mother liquor, a greenish-blue solid was removed by filtration after two days. It was washed several times with water and ethanol, and dried in vacuo. Anal. Calc. for $\mathrm{C}_{6} \mathrm{H}_{12} \mathrm{O}_{9} \mathrm{Cu}$ : C, 24.69; H, 4.11\%. Found: C, 24.31; H, 3.56\%. Yield: $65 \%$.

\subsubsection{CuTCAHImz $\cdot 2 \mathrm{H}_{2} \mathrm{O}$}

A concentrate ethanolic solution of the ligands $(20 \mathrm{~mL})$ containing imidazole ( $1 \mathrm{mmol}, 0.0681 \mathrm{~g}$ ) and $\mathrm{H}_{3}$ TCA (0.5 mmol, $0.088 \mathrm{~g}$ ) was prepared and mixed until complete dissolution. To the mixture, $\mathrm{CuCl}_{2} \cdot 2 \mathrm{H}_{2} \mathrm{O}(0.5 \mathrm{mmol}, 0.085 \mathrm{~g})$ dissolved in $10 \mathrm{~mL}$ of ethanol was gradually added and the final $\mathrm{pH}$ was adjusted to 6 by addition of sodium methoxide. The suspension was filtered and the blue product was washed with distilled water and ethanol and dried in vacuo. Anal. Calc. for: $\mathrm{C}_{9} \mathrm{H}_{14} \mathrm{O}_{8} \mathrm{~N}_{2} \mathrm{Cu}$ : C, 32.19; $\mathrm{H}$, 3.98; N, 8.19\%. Found: C, 31.62; H, 4.09; N, 7.96\%. Yield: $82 \%$.

\subsection{Potentiometric titrations}

The potentiometric titrations were performed using aliquots of $25 \mathrm{~mL}$. $\mathrm{NaCl}$ (Merck p.a.) was dried until constant weight and stored in a desiccator. Stock $\mathrm{Cu}(\mathrm{II})$ solutions were standardized with EDTA [25]. All solutions were made in boiled tridistilled water cooled under a constant nitrogen flow. The solutions were freshly prepared prior to their use. Diluted solutions of $\mathrm{HCl}$ (Merck p.a.) were standardized against TRISMA-base (hydroxymethyl aminomethane). Diluted $\mathrm{NaOH}$ solutions were prepared from a saturated $\mathrm{NaOH}$ solution and standardized against the $\mathrm{HCl}$. In order to assess the degree of carbonate contamination, the method of Gran [26] was used. Cell compartments were kept at $25.0 \pm 0.1{ }^{\circ} \mathrm{C}$ with circulating water from a thermostated bath. The ionic strength was fitted at $0.150 \mathrm{M}$ with $\mathrm{NaCl}$ in the solutions. The glass electrode was calibrated by titration of a diluted $\mathrm{HCl}$ solution of known concentration with a standard base solution. It was checked separately in a solution with known $\left[\mathrm{H}^{+}\right]$before and after each titration.

The formation constants denoted $\beta_{\text {pqrs }}$ correspond to the general notation

$\mathrm{pCu}^{2+}+\mathrm{qTCA}^{3-}+\mathrm{rImz}+\mathrm{sH}^{+} \rightleftharpoons\left(\mathrm{Cu}^{2+}\right)_{\mathrm{p}}\left(\mathrm{TCA}^{3-}\right)_{\mathrm{q}}(\operatorname{Imz})_{\mathrm{r}}\left(\mathrm{H}^{+}\right)_{\mathrm{s}}$

A value of $\mathrm{pK}_{\mathrm{w}}=13.76$ (corresponding to $\log \beta_{000-1}=-13.76$ ) was assumed for the experimental conditions $(T=298 \mathrm{~K}, I=$ $150 \mathrm{mM})$.

The dissociation constants ( $\mathrm{pKa}$ ) for $\mathrm{H}_{3}$ TCA were determined from two sets of titrations of solutions of the ligand (total concentration 5 and $10 \mathrm{mM}$, respectively) in the $\mathrm{pH}$ range $2-11$ being in good concordance with the previously reported data [12]. The acidity constant for $\mathrm{HImz}^{+}$together with the formation constants for the $\mathrm{Cu}^{2+} / \mathrm{Imz} / \mathrm{H}^{+}$system, have been previously determined [27].

In order to determine the formation constants of the $\mathrm{Cu}^{2+} /$ $\mathrm{TCA}^{3-} / \mathrm{H}^{+}$system, four sets of titrations were performed in the $\mathrm{pH}$ range 2-6. Total concentration of copper in the vessel was 2.5, 5 and $10 \mathrm{mM}$ and the metal/ligand concentration ratio was ranged between $1 / 1$ and $1 / 4$. Four titrations of solutions with total copper concentration $2.5 \mathrm{mM}$ were performed on the $\mathrm{Cu}^{2+} / \mathrm{TCA}^{3-}$ / Imz $/ \mathrm{H}^{+}$system. $\mathrm{Cu}^{2+}: \mathrm{H}_{3}$ TCA:Imz concentration ratios were $1: 1: 2$ and $1: 2: 1$, respectively. In order to avoid precipitation at higher $\mathrm{pH}$ values, the $\mathrm{pH}$ range covered was 2-6 in both $\mathrm{Cu}^{2+} / \mathrm{TCA}^{3-}$, $\mathrm{Imz} / \mathrm{H}^{+}$and $\mathrm{Cu}^{2+} / \mathrm{TCA}^{3-} / \mathrm{H}^{+}$systems.

\subsection{SOD assays}

SOD activity was assayed by its ability to inhibit the reduction of nitroblue tetrazolium (NBT) by the superoxide anion generated by the system xanthine/xanthine oxidase, at pH 10.2 (carbonate buffer), reported previously [28,29]. The absorbance of the violet color developed was monitored at $560 \mathrm{~nm}$. Under the same experimental conditions, for comparative purposes, the activity of native SOD from bovine erythrocytes was also measured. All the reagents (Sigma) were used as purchased.

The SOD mimetic activity has been also determined by the nonenzymatic method that differs from the enzymatic in the way of generating the superoxide radical. In this method, the system phenazine methosulfate (PMS)/nicotinamide adenine dinucleotide/reduced $(\mathrm{NADH})$ produces the radical anion. The system 
contains $0.5 \mathrm{~mL}$ of sample, $0.5 \mathrm{~mL}$ of $1404 \mathrm{mM} \mathrm{NADH}, 0.5 \mathrm{~mL}$ of $300 \mu \mathrm{M}$ NBT, in $0.05 \mathrm{M}$ phosphate buffer ( $\mathrm{pH}$ 7.5). After incubation at $25{ }^{\circ} \mathrm{C}$ for $15 \mathrm{~min}$, adding $0.5 \mathrm{~mL}$ of $120 \mu \mathrm{M}$ PMS the reaction starts [30]. Then the reaction mixture is incubated for $5 \mathrm{~min}$. The results are determined by reading the absorbance at $560 \mathrm{~nm}$ against blank samples.

In both methods, the amount of complex that gives a 50\% inhibition of NBT reduction was obtained from a plot of percent inhibition versus complex concentration.

\section{Results and discussion}

\subsection{Chemistry: characterization of the solid compounds}

\subsubsection{Thermogravimetric analysis and diffuse reflectance spectra}

In order to study the thermal stability of the title complexes, thermogravimetric analysis (TG) was performed on polycrystalline samples under an oxygen atmosphere in flowing $\mathrm{O}_{2}(25 \mathrm{~mL})$ with a heating rate of $10^{\circ} \mathrm{C} / \mathrm{min}$ in the temperature range $20-800{ }^{\circ} \mathrm{C}$.

The thermal decomposition of CuTCAH $\cdot 3 \mathrm{H}_{2} \mathrm{O}$ complex shows two stages. The process starts quite early, the first weight loss of $19.32 \%$ occurs in the temperature range $20-100^{\circ} \mathrm{C}$ and it can be attributed to the loss of three water molecules (calculated value of $18.52 \%$ ). Subsequent to this, there is a distinct weight loss stage of $28.01 \%$ (calculated value of $27.27 \%$ ) in which the compound completes the decomposition. It follows that the final product is $\mathrm{CuO}$ that could be identified based on its FTIR spectrum.

For CuTCAHImz $\cdot 2 \mathrm{H}_{2} \mathrm{O}$, thermal analysis exhibits two weight loss stages in the temperature ranges of $20-100{ }^{\circ} \mathrm{C}$ (experimental value $=11.05 \%$, calculated value $=10.54 \%)$ and $100-800^{\circ} \mathrm{C}$ (experimental value $=24.10 \%$, calculated value $=23.27 \%$ ) corresponding to the release of two $\mathrm{H}_{2} \mathrm{O}$ molecules and to the final decomposition, respectively, indicating again that the final residue was $\mathrm{CuO}$ (confirmed by FTIR spectroscopy).

The diffuse reflectance spectrum of $\mathrm{CuTCAH} \cdot 3 \mathrm{H}_{2} \mathrm{O}$ showed the characteristic broad bands for copper(II) complexes located at 710 and $375 \mathrm{~nm}$, and >800, 660, and $365 \mathrm{~nm}$ for CuTCAHImz $\cdot 2 \mathrm{H}_{2} \mathrm{O}$. In both complexes, the broad band observed at low energy is assigned to the d-d transitions of the copper atom (450-830 nm region) and the position of the bands are in accordance with the presence of oxygen atoms ( $\left.\mathrm{CuTCAH} \cdot 3 \mathrm{H}_{2} \mathrm{O}\right)$ and oxygen and nitrogen atoms (CuTCAHImz $\cdot 2 \mathrm{H}_{2} \mathrm{O}$ ) in the coordination sphere of the complexes [31].

\subsubsection{Infrared spectra}

The characteristic bands of the free ligand $\left(\mathrm{H}_{3} \mathrm{TCA}\right)$ at 1731 (vs), 1722(vs) and 1703(vs) $\mathrm{cm}^{-1}$, assigned to the $v(\mathrm{C}=0)$ stretching mode of the carboxylic group $(-\mathrm{COOH})$, disappear upon carboxylate formation. In the sodium salt the spectrum shows two new components corresponding to antisymmetric and symmetric stretching modes of the carboxylate moiety, one strong and broad band at $1573 \mathrm{~cm}^{-1}\left(v_{\mathrm{as}} \mathrm{COO}^{-}\right)$and the other at $1406 \mathrm{~cm}^{-1}\left(v_{\mathrm{s}}\right.$ $\mathrm{COO}^{-}$) as it is expected for the presence of the carboxylate group in its ionic form [32]. General broadening is observed, surely enhanced by the presence of $\delta\left(\mathrm{H}_{2} \mathrm{O}\right)$ vibrations, which are expected to lie between 1600 and $1650 \mathrm{~cm}^{-1}$ [33].

CuTCAH $\cdot 3 \mathrm{H}_{2} \mathrm{O}$ complex exhibits various interesting and important changes in the middle region of the spectrum. Some aspects of the performed assignments are commented:

At $1710 \mathrm{~cm}^{-1}$, one band related to the characteristic $v(\mathrm{C}=0)$ stretching mode remains unchanged.

At lower frequencies, the disappearance of two bands related to $-\mathrm{COOH}$ stretching and the appearance of a set of new bands located at 1636(vs), 1553(vs), 1424(s) and 1413(vs) $\mathrm{cm}^{-1}$ are observed, confirming the participation of two carboxylate group in the coordination sphere. Hence, the spectral splitting is probably caused by the presence of nonequivalent carboxylate groups [34].

Similar changes are observed in CuTCAHImz $\cdot 2 \mathrm{H}_{2} \mathrm{O}$ complex with the splitting of the bands related to the free carboxylic group 1619, 1571 and $1413,1394 \mathrm{~cm}^{-1}$.

The participation of imidazole in the coordination sphere of the CuTCAHImz $\cdot 2 \mathrm{H}_{2} \mathrm{O}$ complex is demonstrated through the behavior of the $936 \mathrm{~cm}^{-1}$ ring mode band of free imidazole. This band is strongly dependent on the coordination geometry of the complexes, being displaced to higher energies after coordination [35] (953 $\mathrm{cm}^{-1}$ in the present case). Furthermore, the new bands located at 3150,1071 and $1278 \mathrm{~cm}^{-1}$ assigned to $v(\mathrm{NH}), \delta_{\mathrm{ip}}(\mathrm{CH})$ and $\delta$ (ring), respectively, have been taken as an evidence of the presence of imidazole in the metal environment [36].

\subsubsection{Electron spin resonance spectra}

The X- and Q-band EPR powder spectra of CuTCAH $\cdot 3 \mathrm{H}_{2} \mathrm{O}$ and CuTCAHImz $\cdot 2 \mathrm{H}_{2} \mathrm{O}$ have been measured at room temperature and at $140 \mathrm{~K}$. The polycrystalline sample of $\mathrm{CuTCAH} \cdot 3 \mathrm{H}_{2} \mathrm{O}$ shows a better resolution in Q-band (Fig. 1). Simulation has shown that the complex exhibits monomer type of signal, having axial symmetry with $g$ values of $g_{\|}=2.416$ and $g_{\perp}=2.091\left(g_{\|}>g_{\perp}\right)$ typical of square pyramidal $\mathrm{Cu}(\mathrm{II})$ complexes with $\mathrm{d}_{x^{2}-y^{2}}$ ground state [37]. The observed broadening of the resonance line suggests an enhanced magnetic dipole interaction between the paramagnetic centers $[37,38]$. Further, in an axial symmetry the ratio of $g$-values, $\boldsymbol{G}=\left(g_{\|}-2\right) /\left(g_{\perp}-2\right)$, provides an indication about the magnitude of the exchange interactions between copper centers in the polycrystalline solid. According to Hathaway [37] a $\boldsymbol{G}$ value less than four indicates a considerable exchange interaction in the solid complexes, while a higher value indicates that the magnetic interaction is negligible. In this case a value of $\boldsymbol{G}=4.57$ suggests that there is no interaction between copper centers.

The simulated spectra for the Q-band of CuTCAHImz $\cdot 2 \mathrm{H}_{2} \mathrm{O}$ (Fig. 2) shows rhombic symmetry with $g_{1}=2.069, g_{2}=2.122$ and $g_{3}=2.272$. The lowest $g>2.04$ can be observed for a copper(II) ion in elongated rhombic symmetry [37]. In order to distinguish the geometry the $\boldsymbol{R}$ parameter $\left(\boldsymbol{R}=\left(g_{2}-g_{1}\right) /\left(g_{3}-g_{2}\right)\right)$ [39] was calculated taking into account $g_{3}>g_{2}>g_{1}$. The $R$ value of 0.33 indicates that the unpaired electron is located mostly on $d_{x^{2}-y^{2}}$

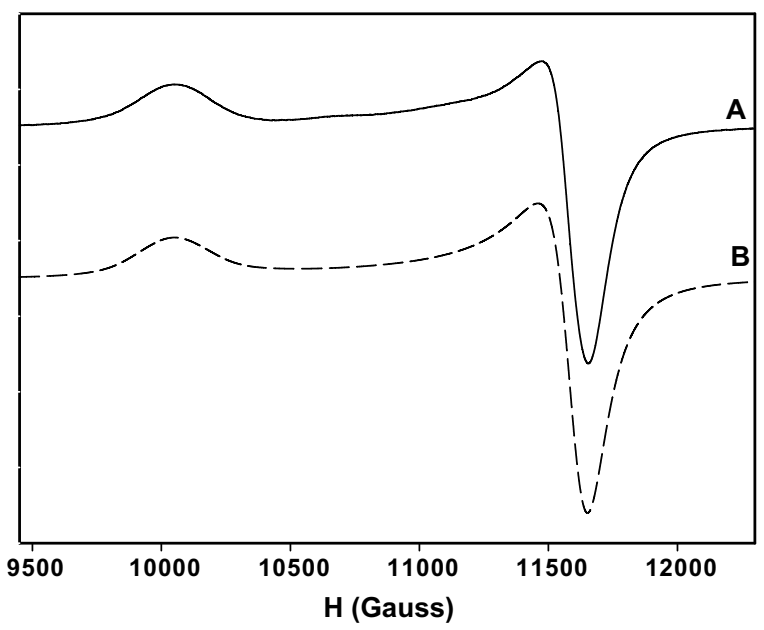

Fig. 1. (A) EPR powder spectra at $300 \mathrm{~K}$ of the complex $\mathrm{CuTCAH} \cdot 3 \mathrm{H}_{2} \mathrm{O}$ and (B) simulated spectrum of (A) WINEPR SimFonia. 


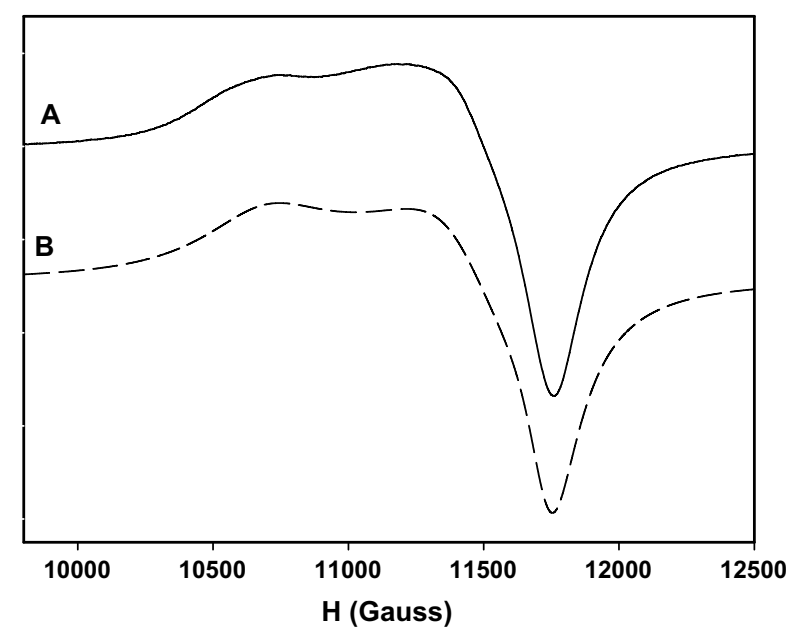

Fig. 2. (A) EPR powder spectra at $300 \mathrm{~K}$ of the complex CuTCAHImz $\cdot 2 \mathrm{H}_{2} \mathrm{O}$ and (B) simulated spectrum of (A) WINEPR SimFonia.

orbital of the copper(II) atom and it is related to square-based pyramidal stereochemistries [37].

\subsection{Solution speciation profiles}

\subsubsection{Stability constants and electron paramagnetic resonance} measurements

The complete proposed speciation model for the $\mathrm{Cu}^{2+} / \mathrm{TCA}^{3-} /$ $\mathrm{Imz} / \mathrm{H}^{+}$system and the corresponding formation constants for the species are shown in Table 1 . All the subsystems under the same experimental conditions were also investigated.

Although the aqueous equilibrium of the ligands has been extensively studied, deprotonation constants were recalculated from different sets of titrations and using Best calculation program [40]. The calculated data of the tricarballylic acid $\left(\mathrm{H}_{3}\right.$ TCA: $\left.\mathrm{pK}_{1}=3.4, \quad \mathrm{pK}_{2}=4.43, \quad \mathrm{pK}_{3}=5.61\right)$ and imidazole $\left(\mathrm{ImzH}^{+}\right.$: $\mathrm{pK}=7.24$ ) are in accordance with reported data $[12,40]$ (Table 1 ).

In order to determine the formation constants of the $\mathrm{Cu}^{2+}$ / $\mathrm{TCA}^{3-} / \mathrm{H}^{+}$and $\mathrm{Cu}^{2+} / \mathrm{Imz} / \mathrm{H}^{+}$and $\mathrm{Cu}^{2+} / \mathrm{TCA}^{3-} / \mathrm{Imz} / \mathrm{H}^{+}$systems, data collected from several sets of titrations were analyzed with Best and Superquad calculation programs [40]. Data was collected from acidic conditions up to $\mathrm{pH} 6$, to avoid precipitation that starts at this early $\mathrm{pH}$ value, even when low concentrations of $\mathrm{Cu}^{2+}$ were used $(2.5 \mathrm{mM})$. The usual criteria for this kind of programs $\left(\mathrm{CHI}^{2}\right.$,

Table 1

Composition, notation and formation constants $(\beta)$ for $\mathrm{Cu}^{2+} / \mathrm{TCA}^{3-}(\mathrm{L})$ and $\mathrm{Cu}^{2+} /$ $\mathrm{TCA}^{3-}(\mathrm{L}) / \mathrm{Imz}(\mathrm{A}) / \mathrm{H}^{+}$system $\left(0.150 \mathrm{M} \mathrm{NaCl}, 25^{\circ} \mathrm{C}\right)$.

\begin{tabular}{llr}
\hline Species pqrs & Formula $^{\mathrm{a}}$ & $\log \beta$ \\
\hline 0011 & $\mathrm{AH}^{+}$ & 7.24 \\
0101 & $\mathrm{LH}$ & 5.61 \\
0102 & $\mathrm{LH}_{2}^{-}$ & 10.04 \\
0103 & $\mathrm{LH}_{3}$ & 13.44 \\
1010 & {$\left[\mathrm{CuA}^{2+}(\mathrm{VIII})\right.$} & 4.43 \\
1020 & {$\left[\mathrm{CuA}_{2}\right]^{2+}(\mathrm{IX})$} & 7.77 \\
1030 & {$\left[\mathrm{CuA}_{3}\right]^{2+}$} & 10.95 \\
1040 & {$\left[\mathrm{CuA}_{4}\right]^{2+}$} & 12.60 \\
1102 & {$\left[\mathrm{CuLH}_{2}\right]^{+}(\mathrm{I})$} & 11.55 \\
1101 & {$\left[\mathrm{CuLH}^{-}(\mathrm{II})\right.$} & 7.82 \\
1100 & {$\left[\mathrm{CuL}^{-}(\mathrm{III})\right.$} & 3.27 \\
2100 & $\left.[\mathrm{Cu}]_{2}\right]^{+}(\mathrm{IV})$ & 5.60 \\
$110-1$ & {$[\mathrm{CuLOH}]^{2-}(\mathrm{V})$} & -3.70 \\
1120 & {$[\mathrm{CuLA}]^{-}(\mathrm{VI})$} & 10.95 \\
1110 & {$\left[\mathrm{CuLA}^{-}(\mathrm{VII})\right.$} & 6.68
\end{tabular}

a Identification labels in the distribution diagrams, in parenthesis.
$R$ values, standard deviations, etc.) were used to select the speciation model.

The results for both $\mathrm{Cu}^{2+} / \mathrm{Imz} / \mathrm{H}^{+}$and $\mathrm{Cu}^{2+} / \mathrm{TCA}^{3-} / \mathrm{H}^{+}$systems in the actual experimental conditions are in good agreement with the literature [41]. In a first attempt, evaluation of titration data obtained for the $\mathrm{Cu}^{2+} / \mathrm{TCA} / \mathrm{H}+$ system was performed assuming only mononuclear complexes in solution: $\left[\mathrm{CuLH}_{2}\right]^{+},[\mathrm{CuLH}],[\mathrm{CuL}]^{-}$, $[\mathrm{CuL}(\mathrm{OH})]^{2-}$ (L denotes the completely deprotonated ligand). Nevertheless, the fitting further improved when the dinuclear $\mathrm{Cu}_{2} \mathrm{~L}^{+}$ species was also included in the model.

Based on the data obtained for the above-mentioned subsystems and reported results for related systems [41-44], several models for the $\mathrm{Cu}^{2+} / \mathrm{TCA}^{3-} / \mathrm{Imz} / \mathrm{H}^{+}$equilibrium has been tested in this work.

The species distribution diagrams as a function of $\mathrm{pH}$, in the 2-6 range, were obtained with SPECIES program and are depicted in Fig. 3 for $\mathrm{Cu}^{2+}-\mathrm{TCA}$ and in Fig. 4 for $\mathrm{Cu}^{2+}-\mathrm{TCA}-\mathrm{Imz}$ systems. Two species $[\mathrm{CuLA}]^{-}$and $\left[\mathrm{CuLA}_{2}\right]^{-}$are formed probably by addition to the $[\mathrm{CuL}]^{-}$complex of one and two imidazole molecules, respectively. They are always minor species that appear in solution at a $\mathrm{pH}$ range in which $[\mathrm{CuL}]^{-}$is dominant.

EPR spectra of the aqueous solution at $140 \mathrm{~K}$ were recorded at different $\mathrm{pH}$ values in order to assist in the identification of different cupric species and the corresponding geometries, particularly, equatorial ligand donor set and the overall charges. The variation of the EPR spectra with the $\mathrm{pH}$ is shown in Fig. 5. Table 2 shows the EPR parameters. An increase in $A_{\|}$values and a decrease in both $g_{\|}$and $g_{x, y}$ components in comparison to free $\left[\mathrm{Cu}\left(\mathrm{H}_{2} \mathrm{O}\right)_{6}\right]^{2+}$ were both observed [45]. These changes are in accordance with the presence of stronger ligand field donor atoms that replace the weak $\mathrm{O}$ atoms of water molecules in the equatorial coordination around the copper(II) ion. Additionally, the increase in energy of the $\mathrm{d}_{x y^{2}} \rightarrow \mathrm{d}_{x^{2}-y^{2}}$ electronic transition, produces a decrease in $g_{\|}$, and

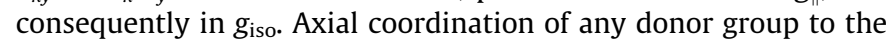
metal ion has only minor effects on $g_{\text {iso }}$ [46].

The typical EPR signal for free $\mathrm{Cu}(\mathrm{II})$ aqua ion is depicted in Fig. 5 (curve A). For the $\mathrm{Cu}^{2+} / \mathrm{TCA}^{3-} / \mathrm{H}^{+}$system, in acidic medium ( $\mathrm{pH} 3$, curve B), two EPR signals can be observed with the typical four band pattern corresponding to an axial $g$ tensor with hyperfine splitting due to the nuclear spin of copper(II) $(I=3 / 2)$. The first signal is related to the presence of the predominant free $\left[\mathrm{Cu}\left(\mathrm{H}_{2} \mathrm{O}\right)_{6}\right]^{2+}$ ion [47] (Table 2) and the other one shows that a new paramagnetic species has been formed. According to the

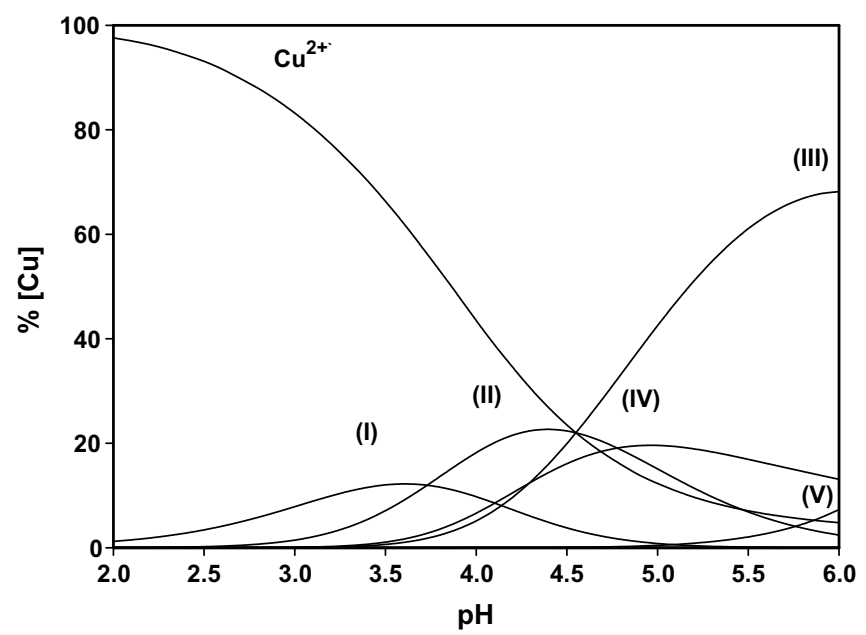

Fig. 3. Species distribution for the $\mathrm{Cu}^{2+} / \mathrm{TCA}^{-3} / \mathrm{H}^{+}$system as a function of $\mathrm{pH}$. Total concentration $\mathrm{Cu}^{2+}: 10 \mathrm{mM}, \mathrm{H}_{3} \mathrm{TCA}: 20 \mathrm{mM}, 25^{\circ} \mathrm{C}, I=0.150 \mathrm{M} \mathrm{NaCl}$. $\left[\mathrm{CuLH}_{2}\right]^{+}(\mathrm{I})$, $[\mathrm{CuLH}](\mathrm{II}),\left[\mathrm{CuL}^{-}\right](\mathrm{III}), \mathrm{Cu}_{2} \mathrm{~L}^{+}(\mathrm{IV})$ and $[\mathrm{CuLOH}]^{2-}(\mathrm{V})$. 


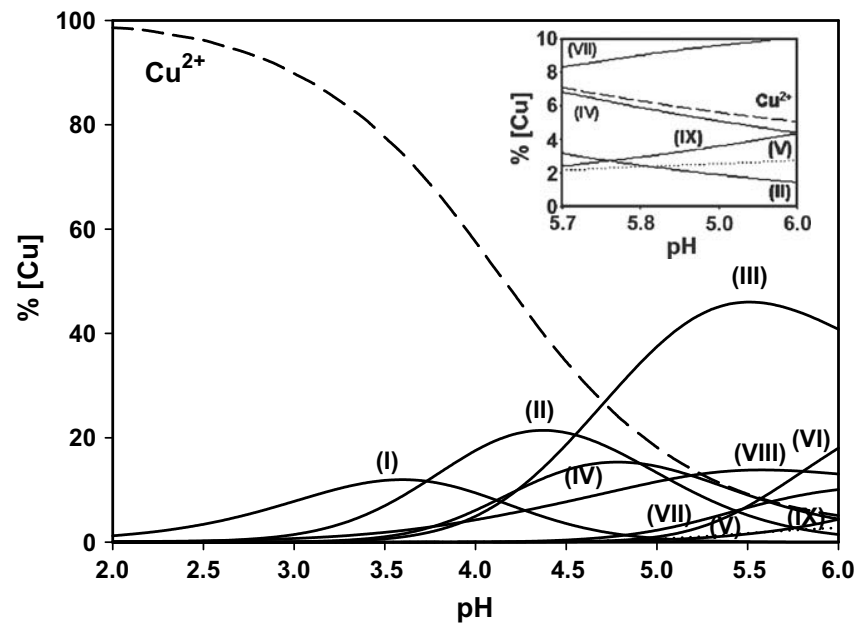

Fig. 4. Species distribution for the $\mathrm{Cu}^{2+} / \mathrm{TCA}^{-3} / \mathrm{Imz} / \mathrm{H}^{+}$system. Total concentration $\mathrm{Cu}^{2+}: 5 \mathrm{mM}, \mathrm{H}_{3}$ TCA: $10 \mathrm{mM}$ and Imz: $5 \mathrm{mM}$ as a function of $\mathrm{pH}, 25^{\circ} \mathrm{C}, I=0.150 \mathrm{M}$ $\mathrm{NaCl}$ [ $\left[\mathrm{CuLH}_{2}\right]^{+}(\mathrm{I}),[\mathrm{CuLH}](\mathrm{II}),\left[\mathrm{CuL}^{-}\right]$(III), $\mathrm{Cu}_{2} \mathrm{~L}^{+}(\mathrm{IV}),[\mathrm{CuLOH}]^{2-}(\mathrm{V}),\left[\mathrm{CuLA}_{2}\right]^{-}(\mathrm{VI})$, $[\mathrm{CuLA}]^{-}(\mathrm{VII}),[\mathrm{CuA}]^{2+}(\mathrm{VIII})$ and $\left[\mathrm{CuA}_{2}\right]^{2+}(\mathrm{IX})$. Inset, the amplified region between pH 5.7 and $\mathrm{pH} 6$.

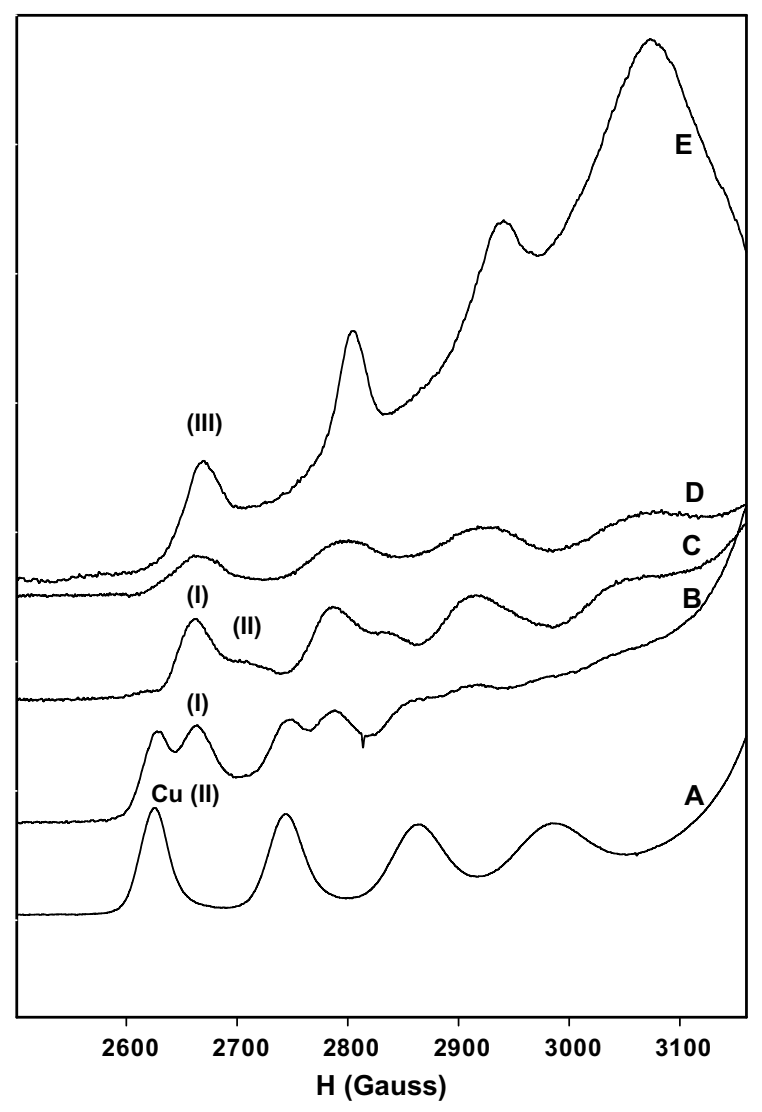

Fig. 5. X-band EPR spectra ( $A_{\|}$region) of the of TCA-copper(II) frozen solutions $\left(140 \mathrm{~K}\right.$ ) in ratio $R=2$, (A) free $\left[\mathrm{Cu}\left(\mathrm{H}_{2} \mathrm{O}\right)_{6}\right]^{2+}$, (B) $\mathrm{pH} 3$, (C) $\mathrm{pH} 3$, difference spectrum, (D) $\mathrm{pH} 4.6$ difference spectrum and (E) $\mathrm{pH}$. Total concentration $\mathrm{Cu}^{2+}: 10 \mathrm{mM}$, $\mathrm{H}_{3}$ TCA: $20 \mathrm{mM}$.

distribution diagram this signal corresponds to the presence of $\left[\mathrm{CuLH}_{2}\right]^{+}(\mathrm{I})$ in agreement with the fact that complexation starts at low $\mathrm{pH}$ in the experimental conditions. Taking into account the EPR parameters and the Blumberg-Peisach approach [48], $\boldsymbol{f}=g_{\|} / A_{\|}\left(\mathrm{cm}^{-1}\right)$ (being $\boldsymbol{f}$ tetragonal distortion factor), the species could be interpreted assuming an equatorial ligand interaction via the $-\mathrm{COO}^{-}$moiety with four $\mathrm{O}$ atoms in the planar donor set and a overall charge of +1 , in good concordance with the stoichiometry proposed for this species in the potentiometric study.

The increase of the $\mathrm{pH}$ value induces important variations on EPR features of the cupric ion (curve A); two new resonance lines appear, but there is still free copper(II) aquoion overlapping the signal (curve B). In order to identify the species difference spectrum were performed (curve $\mathrm{C}$ ). As it can be seen the spectrum allows the identification of $\left[\mathrm{CuLH}_{2}\right]^{+}$that remains in significant quantities and a new species proposed as [CuLH] (II) based on $g_{\|} / A_{\|}$ $(\mathrm{cm})$ ratio. In the latter species two of the carboxylate groups of the ligand are deprotonated allowing mono or bidentate coordination to the metal. Upon increasing the $\mathrm{pH}$ value of the solution the spectral feature becomes broader and the relative intensity of the signals decreases (curve D). Probably, the presence of the dinuclear species $\left(\mathrm{Cu}_{2} \mathrm{~L}^{+}\right)(\mathrm{IV})$, that starts to be predominant, leads to signal extinguishing due to the paramagnetic $\mathrm{Cu}(\mathrm{II})$ center interactions $[47,49]$. Typical $\Delta \mathrm{Ms}= \pm 2$ forbidden transition was expected to appear at half field. However, due to the low concentration of the solutions it was not observed. In agreement with related polycarboxylate dinuclear complexes [50], the binding mode of this species probably involves a carboxylate bridge. At higher $\mathrm{pH}$ (curve E) it is also possible to detect [CuL] ${ }^{-}$(III) as the majority species (Table 1 ). At this $\mathrm{pH}$ value, a hydroxo complex $[\mathrm{CuLOH}]^{2-}(\mathrm{V})$ is also predicted as a minor species by the speciation model. Nevertheless, due to overlapping with the previous cupric complex that predominates in this experimental condition, it is not EPR detectable. The trend of $g_{\|} / A_{\|}$ratio is in accordance with the one expected for the increases of the negative charge of the cubic ligand field [47]. These results are in agreement with the proposed model by the potentiometric data analysis.

The behavior of the $\mathrm{Cu}^{2+} / \mathrm{TCA}^{3-} / \mathrm{Imz} / \mathrm{H}^{+}$system is better described in the distribution diagram. Fig. 4 shows the speciation for total concentrations used to perform the EPR measurements. At low $\mathrm{pH}$ range the sequence of formation of the species is similar to that observed in the $\mathrm{Cu} / \mathrm{TCA} / \mathrm{H}^{+}$system. The slight differences can be attributed to different relative concentrations of the species present in solution. From Fig. 6(1) it can be seen that there appeared two new signals at $\mathrm{pH}$ 5.3: $\mathrm{CuL}^{-}$(III) denoted as (A) and (B), both in curve (i) showing the presence of new chemical species in solution. The isolated new signal is shown in the EPR spectra despicted in Fig. 6(1), curve (iii) and their origin probably involves the equilibrium of the species containing $\mathrm{N}$ donor atoms in the coordination sphere. These signals are also present at higher $\mathrm{pH}$ values (Fig. 6(1), curve (iv)). This discussion is also consistent with the EPR spectra recorded at pH 6. Curve (iv) in Fig. 6(2) shows the existence of nitrogen superhyperfine structure not well resolved in the high magnetic field region of the EPR spectrum. Unfortunately, in the experimental conditions we could not detect the individual signals related to the chemicals species predicted in the speciation model at $\mathrm{pH}>5.3$. The observed signal in the spectrum can be seen as the superimposition of the individual signals of species with very similar parameters and with comparable coordination modes. Moreover, the best fit for the spectra $\left(g_{\|}=2.320, \quad\left(A_{\|}=165 \times\right.\right.$ $10^{-4} \mathrm{~cm}^{-1}$ ) has been obtained considering the interaction of the metal center with nitrogen donor atoms [51].

Even when the stoichiometry of the solid CuTCAHImz $\cdot 2 \mathrm{H}_{2} \mathrm{O}$ complex cannot be predicted from the speciation model, it should be stated that the synthesis was performed in ethanolic solution, at very different experimental conditions than for potentiometric and EPR measurements. Nevertheless, it can be pointed out that the metal to ligand ratio in the solid compound is coincident with the minor species $(1,1,1,0)$ in aqueous solution. Probably, the uncharged $(1,1,1,1)$ species once formed in ethanol, precipitate because of the lowest solubility in the preparative conditions. 
Table 2

EPR parameters for the copper(II)/ $\mathrm{H}_{3} \mathrm{TCA}\left(\mathrm{H}_{3} \mathrm{~L}\right)$ system.

\begin{tabular}{|c|c|c|c|c|c|c|c|c|c|}
\hline & $g(x)$ & $g(y)$ & $g(z)$ or $g_{\|}$ & $g_{\text {iso }}$ & $A(x)$ & $A(y)$ & $A(z)$ or $A_{\|}\left(\mathrm{cm}^{-1}\right)$ & $A_{\text {iso }}$ & $\boldsymbol{f}=g_{\|} / A_{\|}(\mathrm{cm})$ \\
\hline $\mathrm{Cu}(\mathrm{II})$ & 2.085 & 2.085 & 2.418 & 2.196 & 7 & 7 & 135 & 49.66 & 179 \\
\hline$\left[\mathrm{CuLH}_{2}\right]^{+}(\mathrm{I})$ & 2.076 & 2.076 & 2.38 & 2.177 & 16 & 16 & 138 & 56.66 & 172 \\
\hline [CuLH] (II) & 2.074 & 2.074 & 2.335 & 2.161 & 10 & 10 & 142 & 54 & 164 \\
\hline$\left[\mathrm{CuL}^{-}\right]$(III) & 2.085 & 2.085 & 2.36 & 2.176 & 30 & 30 & 150 & 70 & 157 \\
\hline
\end{tabular}
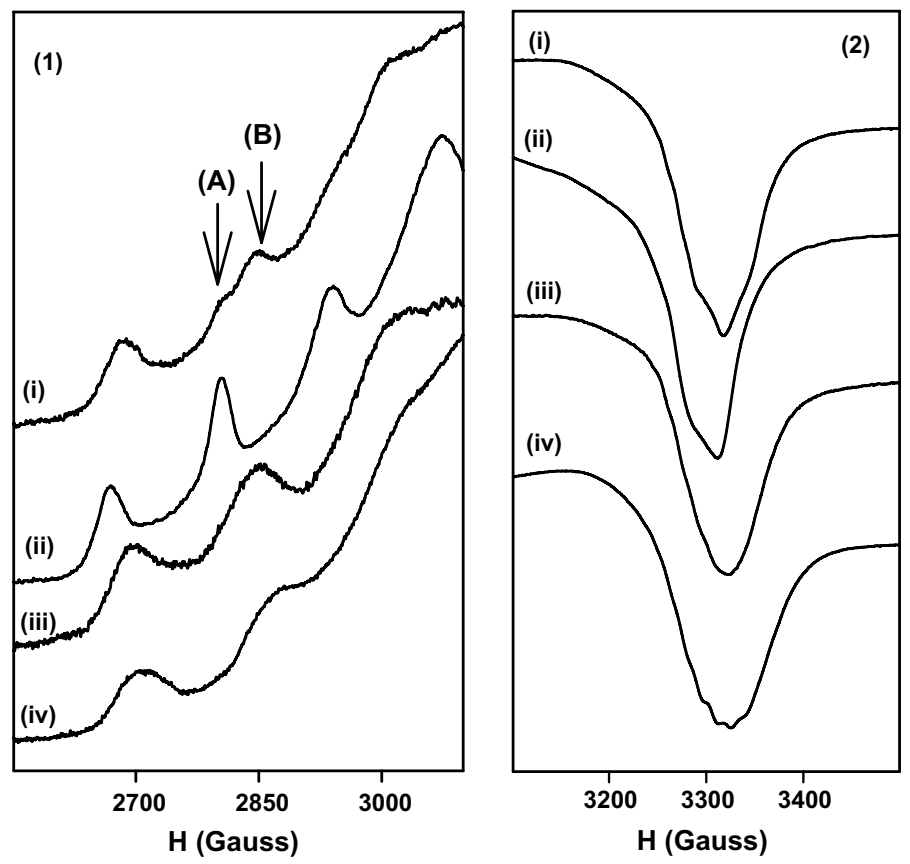

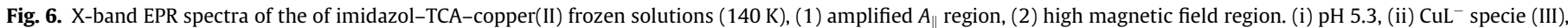
difference spectrum, (iii) $\mathrm{pH}$ 5.5, difference spectrum, (iv) $\mathrm{pH}$ 6, difference spectrum. Total concentration $\mathrm{Cu}^{2}+: 5 \mathrm{mM}, \mathrm{H}_{3} \mathrm{TCA}: 10 \mathrm{mM}$, Imz: $5 \mathrm{mM}$.

\subsection{Superoxide dismutase-mimetic activity}

The mechanism proposed for the dismutation of superoxide anions by both SOD and the metal complex is thought to involve redox cicling of copper(II) ions

$$
\begin{aligned}
& \mathrm{Cu}(\mathrm{II})+\mathrm{O}_{2}^{--} \rightleftharpoons \mathrm{Cu}(\mathrm{I})+\mathrm{O}_{2} \\
& \mathrm{Cu}(\mathrm{I})+\mathrm{O}_{2}^{--}+2 \mathrm{H}^{+} \rightleftharpoons \mathrm{Cu}(\mathrm{II})+\mathrm{H}_{2} \mathrm{O}_{2}
\end{aligned}
$$

It has been proposed that electron transfer between copper(II) and superoxide anion radicals occurs through direct binding. The axial site of copper(II) complex is the likely attachment point for $\mathrm{O}_{2}^{--}$. Other dimeric complexes have weakly bonded axial ligands which are dissociated to provide sites on $\mathrm{Cu}(\mathrm{II})$ for $\mathrm{O}_{2}^{-}$bonding. The copper(II) arrangement facilitates the interaction with the radical and their dissociation to oxygen and hydrogen peroxide. The fast exchange of axial solvent molecules and a limited steric hindrance to the approach of the $\mathrm{O}_{2}^{--}$in those complexes give rise to better SOD mimics [52].

The superoxide dismutase-mimetic activity of the complexes was measured using the xanthine/xanthine-oxidase/NBT assay system [53]. NBT acts as superoxide detecting agent through its reduction to methyl formazan $\left(\mathrm{MF}^{+}\right)$. The color changes from yellow to violet and it is associated with an increase in the absorption at $560 \mathrm{~nm}$ in the electronic spectrum. When a chemical inhibitor is added the reduction reaction proceeds slowly or is totally inhibited. In this instance, the solution remains yellow and the rate of absorption increment is reduced with increasing concentration of the complex. In order to determine the complex concentration required yielding a $50 \%\left(\mathrm{IC}_{50}\right)$ inhibition of the reaction, percentage of inhibition as a function of the logarithm of the metal concentration was plotted (Fig. 7). The $100 \%$ of superoxide dismutase activity corresponds to an assay performed in the absence of the complex. It was found that $\mathrm{Cu}(\mathrm{II})$ concentration of native-SOD of $8.5 \times 10^{-8} \mathrm{M}$ is required to produce a $50 \%$ an inhibition of the reaction [54]. A value of $4.68 \times 10^{-4} \mathrm{M}$ was needed for the CuT$\mathrm{CAH} \cdot 3 \mathrm{H}_{2} \mathrm{O}$ complex (Fig. 7A), indicating moderate SOD mimics activity. Copper concentration higher than $10^{-3} \mathrm{M}$ interferes in SOD activity measurements. Nevertheless, it can be seen from the Fig. $7 \mathrm{~A}$ that at this concentration a $100 \%$ inhibition in SOD activity is produced.

On the other hand, the CuTCAHImz $\cdot 2 \mathrm{H}_{2} \mathrm{O}$ complex (Fig. 7A) showed similar SOD activity giving a value of $3.39 \times 10^{-4} \mathrm{M}$ for $\mathrm{IC}_{50}$

Taking into account that a small amount of $\mathrm{O}_{2}^{--}$is produced in the xanthine/xanthine oxidase system [55], the assay was carried out in a nonenzymatic method at $\mathrm{pH}$ 7.5. In this test, superoxide anion radicals were generated by the reaction of NADH with PMS, and detected through the reduction of NBT in a similar way of the enzymatic assay. In this experimental condition, the scavening data obtained for CuTCAH $\cdot 3 \mathrm{H}_{2} \mathrm{O}$ complex $\left(\mathrm{IC}_{50}=5.1 \times 10^{-6} \mathrm{M}\right)$ and CuTCAHImz $\cdot 2 \mathrm{H}_{2} \mathrm{O}$ complex $\left(\mathrm{IC}_{50}=7.24 \times 10^{-6} \mathrm{M}\right.$ ) (Fig. 7B) indicate that both compounds exhibit a moderate superoxide dismutase activity. Although complexes were not as efective as the enzyme (bovine erythrocyte SOD, $\mathrm{IC}_{50}=2.1 \times 10^{-7} \mathrm{M}$; horseradish SOD, $\left.\mathrm{IC}_{50}=7 \times 10^{-8} \mathrm{M}\right)[54,55]$ the $\mathrm{IC}_{50}$ values are comparable of 

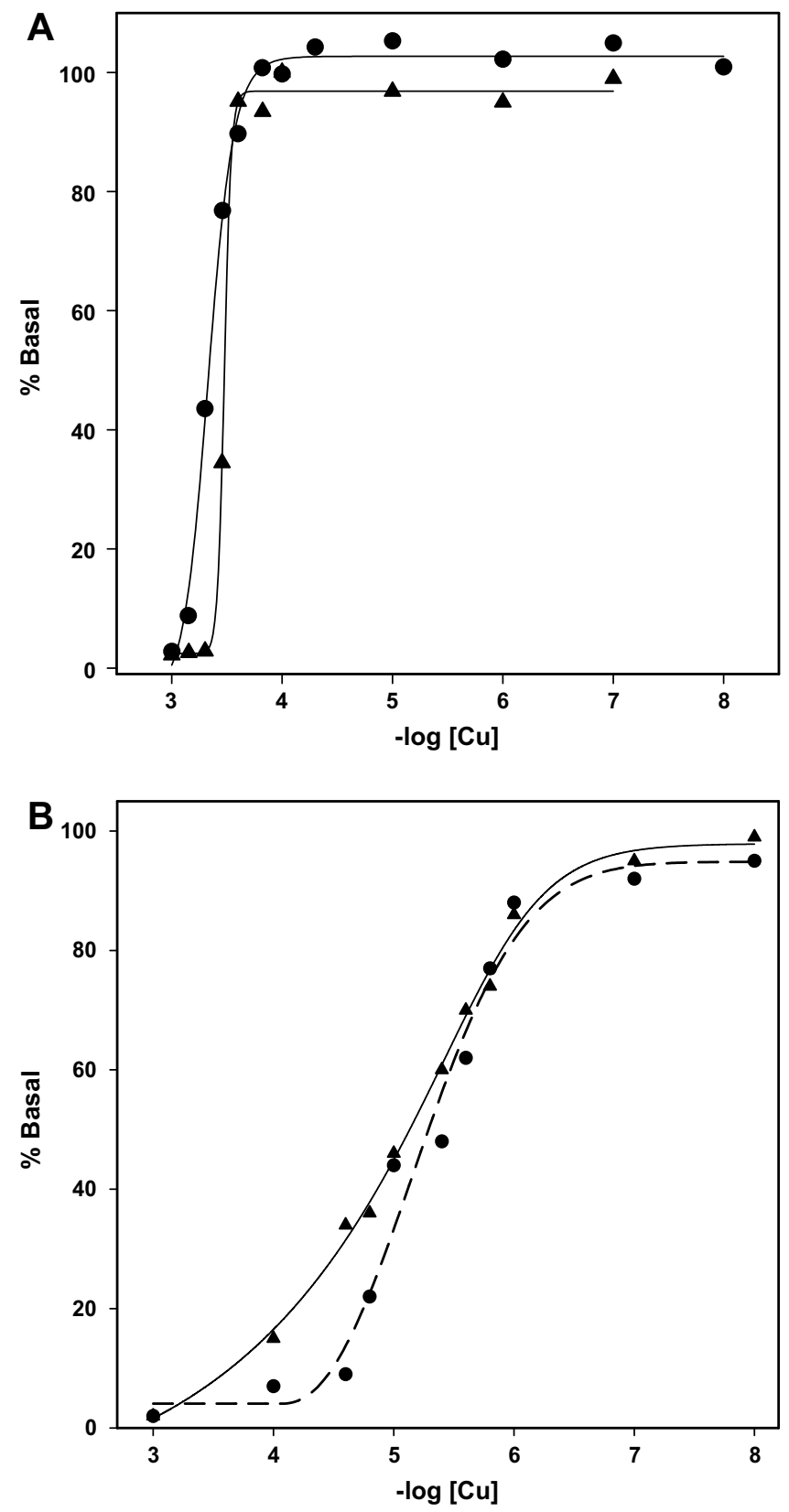

Fig. 7. Percentage of inhibition of the NBT reduction as a function of the logarithm of $\mathrm{Cu}$ (II) concentration for (A) enzymatic assay, pH 10.2: $\mathrm{CuTCAH} \cdot 3 \mathrm{H}_{2} \mathrm{O}(\bullet)$ and CuTCAHImz $\cdot 2 \mathrm{H}_{2} \mathrm{O}(\boldsymbol{\Delta})$ complexes, (B) nonenzymatic assay, pH 7.5: CuTCAH $\cdot 3 \mathrm{H}_{2} \mathrm{O}$ (•) and CuTCAHImz $\cdot 2 \mathrm{H}_{2} \mathrm{O}(\boldsymbol{\Delta})$ complexes.

those obtained for free copper $\left(\mathrm{IC}_{50}=2.1 \times 10^{-6} \mathrm{M}\right)$. The results are consistent with earlier observations that superoxide radical anion scavenging is exhibited by a number of low molecular mass $\mathrm{Cu}(\mathrm{II})$ biomimetic coordination compounds [55,56].

The active species that produces the SOD mimic effect are very difficult to characterize in solution at micromolar concentrations. As it was stated in Section 2, titrations could be performed only up to $\mathrm{pH} 6$, because at millimolar concentrations precipitation of the components is observed at higher $\mathrm{pH}$ values. Nevertheless, considering micromolar concentrations modelling the SOD assays, the species distribution can be extrapolated to higher $\mathrm{pH}$ values. Lower concentrations result in lower complexation extent for both investigated systems, reaching approximately $20 \%$ of $\mathrm{Cu} / \mathrm{TCA}$ species at $\mathrm{pH} 7.5$, being $11-1$ and 110 the species predicted in solu- tion. For the Cu/TCA/Im system at the same $\mathrm{pH}$, almost $30 \%$ of complexed species are involved in the 1010 and 1100 species.

The speciation analysis allows predicting partial complexation and the coexistence of various species in solution in the experimental conditions of SOD assays. The SOD activity can then be attributed to a different species including free copper. Therefore, the new complexes showed similar behavior than solution of copper chloride.

\section{Conclusions}

We have studied the interaction of $\mathrm{Cu}^{2+}$ with tricarballylic acid in solution for the $\mathrm{Cu}^{2+} / \mathrm{TCA}^{3-} / \mathrm{H}^{+}$and $\mathrm{Cu}^{2+} / \mathrm{TCA}^{3-} / \mathrm{Imz} / \mathrm{H}^{+}$systems. The stoichiometries of the various complexes formed in solution were established by potentiometric titrations, being the $1: 1$ metal to ligand ratio the predominant. The binding mode of the species were determined by means of EPR spectroscopic measurements and the obtained results reveal the presence of the mononuclear and dinuclear copper complexes. The values of the formation constants show a higher stability of the species containing $\mathrm{N}$-ligand donor in the coordination set. In both compounds, the environments of the metal were established. Two new solid metal complexes with tricarballylic acid were obtained and characterized. In the $\mathrm{CuTCAH} \cdot 3 \mathrm{H}_{2} \mathrm{O}$ complex axial symmetry has been determined, while in the CuTCAHImz $\cdot 2 \mathrm{H}_{2} \mathrm{O}$ complex rhombic symmetry has been stated. The compounds showed moderate SOD mimetic activity at physiological $\mathrm{pH}$.

\section{Abbreviations}

FTIR Fourier transform infrared spectroscopy

$\mathrm{H}_{3}$ TCA tricarballylic acid, 1,2,3-propanetricarboxylic acid

Imz imidazole

NADH nicotinamide adenine dinucleotide reduced

NBT nitroblue tetrazolium

PMS phenazine methosulfate

SOD superoxide dismutase

TRISMA hydroxymethyl aminomethane

\section{Acknowledgements}

This work was supported by UNLP, CONICET, CICPBA, Ministerio de Educación de la Nación, República Argentina (Proyecto: 06-08038), Eusko Jaularitza/Gobierno Vasco MV-2004-3-39. EGF and AGB are members of the Carrera del Investigador, CONICET. PAMW is a member of the Carrera del Investigador CICPBA, Argentina. L.N. is a fellowship holder from CONICET.

\section{References}

[1] H. Sigel, Properties of copper, in: H. Sigel (Ed.), Metal Ions in Biological Systems, vol. 12, Marcel Dekker, New York, 1981.

[2] S.E. Castillo-Blum, N. Barbra-Behrens, Coord. Chem. Rev. 196 (2000) 3-30.

[3] G. Wilkinson, in: R.D. Gillard, J.A. Mccleverty (Eds.), Comprehensive Coordination Chemistry, The Synthesis, Reactions Properties \& Applications of Coordination Compounds, Pergamon Books Ltd., Oxford, 1987.

[4] S. Abdel-Sattar, H. Elgazwy, Curr. Org. Chem. 8 (2004) 1405-1423.

[5] A.S. Abdel-Sattar, H. Elgazwy, Molecules 5 (2000) 665-673.

[6] J.B. Russel, N. Forsberg, Br. J. Nutr. 56 (1986) 153-162.

[7] R. Schwartz, M. Topley, J.B. Russell, J. Nutr. 118 (1988) 183-188.

[8] B.H. Ye, M.L. Tong, X.M. Chen, Coord. Chem. Rev. 249 (2005) 545-565.

[9] Q.L. Wang, C.Z. Xie, D.Z. Liao, S.P. Yan, Z.H. Jiang, P. Cheng, Transit. Metal Chem. 28 (2003) 16-20.

[10] N.C. Li, A. Lindenbaum, J.M. White, J. Inorg. Nucl. Chem. 12 (1939) 122-128.

[11] K.S. Rajan, A.E. Martell, J. Inorg. Nucl. Chem. 29 (1967) 523.

[12] E. Campi, G. Ostacoli, M. Meironi, G. Saini, J. Inorg. Nucl. Chem. 26 (1964) 553564.

[13] E.E. Kiss, M. Jezowska-Bojczuk, T. Kiss, J. Coord. Chem. 40 (1996) 157-166. 
[14] S.B. Etcheverry, P.A.M. Williams, in: Medicinal Chemistry Research Progress. Medicinal Chemistry of Copper and Vanadium Bioactive Compounds, Nova Science Publishers, Inc., Hauppauge, NY, in press.

[15] J.R.J. Sorenson, Inflammatory Diseases and Copper, Humana Press, Clifton, 1982.

[16] J.R.J. Sorenson, in: H. Sigel (Ed.), The Anti-Inflammatory Activities of Copper Complexes, Metal Ions in Biological Systems, 14, Marcel Dekker, New York, 1982.

[17] B.R. Cameron, I.R. Baird, J. Inorg. Biochem. 83 (2001) 233-236.

[18] R. Bakhtiar, E.I. Ochiai, Gen. Pharmacol. Vasc. S 32 (1999) 525-540.

[19] L. Rulísek, J. Vondrásek, J. Inorg. Biochem. 71 (1998) 115-127.

[20] P.P. Deschamps, P. Kulkarni, B. Sarkar, Inorg. Chem. Commun. 43 (2004) 3338 3340.

[21] H. Ohtsu, Y. Shimazaki, A. Odani, O. Yamauchi, W. Mori, S. Itoh, S. Fukuzumi, J. Am. Chem. Soc. 122 (2000) 5733-5741.

[22] J. Davidge, D.R. Williams, Inorg. Chim. Acta 356 (2003) 109-113.

[23] D.R. Williams, J. Inorg. Biochem. 79 (2000) 275-283.

[24] WINEPR SimFonia v1.25, Bruker Analytische Messtecnik GmbH, 1996.

[25] I.M. Kolthoff, E.B. Sandell, E.J. Meehan, S. Bruckenstein, Análisis Químico Cuantitativo, fifth ed., Librería y editorial Nigar, Buenos Aires, 1979.

[26] G. Gran, Analyst 77 (1952) 661-671.

[27] E.G. Ferrer, A.C. González Baró, E.E. Castellano, O.E. Piro, P.A.M. Williams, J. Inorg. Biochem. 98 (2004) 413-421.

[28] C. Beauchamp, I. Fridovich, Anal. Biochem. 44 (1971) 276-287.

[29] Y. Iwamoto, I. Mifuchi, Chem. Pharm. Bull. 30 (1982) 237-241.

[30] C.C. Kuo, M. Shih, Y. Kuo, W. Chiang, J. Agric. Food. Chem. 49 (2001) 15641570.

[31] A.B.P. Lever, Inorganic Electronic Spectroscopy, second ed., Elsevier, The Netherlands, 1984

[32] K. Nakamoto, Infrared and Raman Spectra of Inorganic and Coordination Compounds, fourth ed., J. Wiley, New York, 1986.

[33] E.G. Ferrer, P.A.M. Williams, E.J. Baran, J. Inorg. Biochem. 50 (1993) 253-262.

[34] T.J. Strathmann, S.C.B. Myneni, Geochim. Cosmochim. Acta 68 (2004) 34413458.

[35] P.A.M. Williams, E.G. Ferrer, M.J. Correa, E.J. Baran, E.E. Castellano, O.E. Piro, J. Chem. Crystallogr. 34 (2004) 285-290.
[36] E.J. Baran, B.S. Parajón-Costa, E.G. Ferrer, L. Lezama, T. Rojo, J. Inorg. Biochem. 63 (1996) 19-27.

[37] B.J. Hathaway, D.E. Billing, Coord. Chem. Rev. 5 (1970) 143-207.

[38] K. Ösz, K. Várnagy, H. Süli-Vargha, A. Csámpay, D. Sanna, G. Micera, I. Sóvágó, J. Inorg. Biochem. 98 (2004) 1655-1666.

[39] S. Chandra, L.K. Gupta, Spectrochim. Acta, Part A 61 (2005) 269-275.

[40] A.E. Martell, R.J. Motekaitis, Determination and Use of Stability Constants, second ed., VCH Publishers Inc., New York, 1992.

[41] A. Martell, R.M. Esmith, Critical Stability Constants, Plenum Press, New York, 1974.

[42] P. Gans, A. Sabatini, A. Vacca, J. Chem. Soc., Dalton Trans. (1985) 1195-1200.

[43] E.B. Gonzalez, L.N. Daeid, K.B. Nolan, E. Farkas, Polyhedron 13 (1994) 14951499.

[44] A. Bavoso, L. Menabue, M. Saladini, M. Sola, Inorg. Chim. Acta 244 (1996) $207-$ 212

[45] J.L. Miranda, J. Felcman, Polyhedron 22 (2003) 225-233.

[46] N.V. Nagy, T. Szabó-Plánka, G. Tircsó, R. Király, Z. Árkosi, A. Rockenbauer, E. Brücher, J. Inorg. Biochem. 98 (2004) 1655-1666.

[47] C. Menidiatis, C. Methenitis, N. Nikolis, G. Pneumatikakis, J. Inorg. Biochem. 98 (2004) 1795-1805.

[48] J. Peisach, W.E. Blumberg, Arch. Biochem. Biophys. 165 (1974) 691-708.

[49] D. Hollender, T.S. Jakusch, A. Buhsina, E. Aboukais, T. Abi Aad, T. Kiss, J. Inorg. Biochem. 85 (2001) 245-251.

[50] I. Vlahou, N. Kourkoumelis, A. Michaelides, S. Skoulika, J.C. Plakatouras, Inorg. Chim. Acta 359 (2006) 35-40.

[51] J.E. Gairin, H. Mazarguil, P. Sharrock, R. Haran, Inorg. Chem. 21 (1982) 18461854.

[52] A.L. Abuhijleh, J. Inorg. Biochem. 68 (1997) 167-175.

[53] J.M. Mc Cord, I. Fridovich, J. Biol. Chem. 242 (1969) 6049-6055.

[54] S.B. Etcheverry, E.G. Ferrer, L. Naso, J. Rivadeneira, V. Salinas, P.A.M. Williams, J. Biol. Inorg. Chem. 13 (2008) 435-447.

[55] I. Schepetkin, A. Potapov, A. Khlebnikov, E. Korotkova, A. Lukina, G. Malovichko, L. Kirpotina, M.T. Quinn, J. Biol. Inorg. Chem. 11 (2006) 499-513.

[56] A. Latif Abubijleb, J. Inorg. Biochem. 68 (1997) 167-175. 